\title{
Alcohol Abuse and the Anxiety Disorders: Evidence From The Epidemiologic Catchment Area Survey
}

\author{
JoSePh A. HIMLE, M.S.W. AND ElizaBeTh M. HIL, Ph.D. \\ University of Michigan
}

\begin{abstract}
This study examined the prevalence of alcohol abuse and/or dependence in a sample of patients with anxiety disorders gathered from the Epidemiologic Catchment Area Study. Prior research had indicated that anxiety disorders are prevalent among alcoholics and also that alcoholism is prevalent among samples of anxiety disorder patients. The sample included 2471 individuals who met a lifetime diagnosis of agoraphobia, panic disorder, agoraphobia with panic attacks, social phobia, simple phobia, or obsessive-compulsive disorder. About $12 \%$ of these individuals met criteria for a lifetime history of alcohol abuse and/or dependence. Relative odds ratios were calculated for the risk of alcohol use disorder, correcting for the effects of site, age, race, and gender. Among those individuals with a history of both anxiety and alcoholism disorders, the highest risk of alcohol use disorder was found in the agoraphobia with panic group. Lowest risk was found among those with a single diagnosis of simple phobia or agoraphobia without panic attacks. Clinical implications of these results are discussed.
\end{abstract}

The purpose of this study was to examine the prevalence of alcohol abuse and/or dependence in a sample of patients with either a single or multiple DSM-III anxiety disorder diagnosis, using a large community-based group. Weissman (1988a) pointed out that both anxiety and alcoholism are common disorders, show gender differences, share similar symptoms, and tend to cooccur in families. Several studies have addressed the question of comorbidity of alcoholism and anxiety disorders by interviewing patients currently in treat-

The Epidemiologic Catchment Area Program (ECA) is a series of five epidemiological research studies performed by independent research teams in collaboration with staff of the Division of Biometry and Epidemiology and the Division of Clinical Research (DCR) of the National Institute of Mental Health (NIMH). The NIMH Prinicpal Collaborators are Darnel A Regier, Ben Z. Loke, and Jack D. Burke, Jr.; the NIMH Project Officer was Carl A. Taube from 1978-1985 and has been William Huber since 1985. The Principal Investigators and Co-Investigators from the five sites are: Yale University, U01 MH34224: Jerome K. Myers, Myrna M. Weissman, and Gary L. Tischler; Johns Hopkins University, U01 MH33870: Morton Kramer and Sam Shapiro; Washington University, St. Louis, U01 MH33883: Lee N. Robins and John Helzer; Duke University, U01 MH35386: Linda George and Dan Blazer, University of California, Los Angeles, U01 MH35865: Marvin Karno, Richard L. Hough, Javier, I. Escobar, M. Audrey Bumam, and Diane M. Timbers. 
ment for alcohol abuse disorders. Stravynski and associates (1986) examined a group of 128 former inpatient, abstinent alcoholics and found that nearly $9 \%$ met criteria for agoraphobia (either with or without panic attacks), while almost $8 \%$ met DSM-III criteria for social phobia. Smail et al. (1984) found that among sixty alcoholics, $39 \%$ met criteria for social phobia and $41 \%$ had met DSM-III criteria for agoraphobia during the most recent drinking period. Almost all of these phobic patients reported that their alcohol use was exacerbated in phobic situations. In a sample of 501 alcohol and/or drug dependant/abusive individuals, Ross and associates (1988) found that $33 \%$ of the patients currently met DSM-III criteria for an anxiety disorder, including obsessive compulsive disorder $(6.3 \%)$, panic disorder $(8.5 \%)$, agoraphobia (18.7\%), agoraphobia with panic attacks (7.0\%), simple phobia (13.2\%), social phobia (9.4\%). Mullaney and Trippett (1979) found that a third of 102 inpatient alcoholics had disabling agoraphobia or social phobia, while Weiss and Rosenberg (1985) found $23 \%$ of 66 inpatient alcoholics met criteria for one or more DSM-III anxiety disorders. Similarly, Nunes and associates (1988) reported that $32 \%$ of 25 female alcoholic inpatients had panic disorder. These prevalence rates are in excess of those found in the general population (Weissman, 1988b; Myers et al., 1984). Helzer and Pryzbeck (1988) assessed comorbidity of alcohol abuse and/or dependence with other disorders using the ECA sample. Alcoholics were found to be twice as likely as the general population to have panic disorder. Boyd (1984), also using the ECA sample, found that, in the month prior to interview, alcoholism and anxiety disorders co-occurred at a rate higher than expected by given prevalence rates of these disorders in the general population.

A second way to study the relationship between anxiety disorders and alcoholism is to evaluate the prevalence of alcohol abuse among samples of anxiety disordered individuals. Schneier and associates (1989) found that 16 of 98 social phobics also met criteria for a lifetime diagnosis of alcoholism using a structured interview. Thyer and associates (1986) administered the Michigan Alcoholism Screening Test (MAST) (Selzer, 1971) to 156 outpatients meeting DSM-III criteria for agoraphobia with panic attacks, panic disorder, simple phobia, social phobia, and generalized anxiety disorder. MAST scores of $\leq 5$, indicating probable alcoholism, were found to be most prevalent statistically among those diagnosed with agoraphobia with panic attacks when compared with panic disorder and generalized anxiety disorder patients. Social phobics were found to have the greatest percentage of individuals with a MAST score of $>5$, but because of their small numbers $(n=11)$ this finding was not statistically significant. Bibb and Chambless (1986) also found a high prevalence ( $21 \%$ ) of MAST scores $\geq 5$ among 254 outpatients suffering from agoraphobia with panic attacks. Using a structured diagnostic interview, Reich and Chaudry (1987) reported that $28 \%$ of 61 patients with panic disorder also had a history of alcohol abuse.

One difficulty with comorbidity studies that also confronts clinicians is the overlap between the symptoms of anxiety disorder and alcohol withdrawal (George et al., 1988; Weissman, 1988a). Establishing that the anxiety disorder temporally preceded the alcoholism helps to reduce diagnostic errors and confusion. Thus, Christie et al. (1988) analyzed young people in the ECA study 
who had comorbid substance use disorder and major depression and/or an anxiety disorder, and found that $75 \%$ reported that the anxiety or depressive disorder preceded development of the substance use disorder. When other investigators evaluated ages of onset of anxiety and alcohol use disorders (Mullaney \& Trippet, 1979; Weiss \& Rosenberg, 1985; Hesselbrock et al., 1985; Schneier et al., 1989), they also found that the majority of individuals developed the drinking problem following onset of the anxiety disorder. This temporal sequence lends support to the tension reduction model of alcohol use (Hodgson et al., 1979; Stockwell et al., 1982). The tension reduction hypothesis coupled with the clinical findings related to alcoholism and anxiety disorders reviewed above, demonstrate the need to investigate the prevalence of alcohol abuse and dependence in a larger community-based sample.

\section{METHOD}

\section{Subjects}

This sample was obtained from the public data on the first-wave community sample of the National Institute of Mental Health Epidemiologic Catchment Area Program. All individuals with a DSM-III anxiety disorder diagnosis were selected. For this analysis we included everyone who met severity and exclusion criteria for lifetime diagnosis of agoraphobia, panic disorder, agoraphobia with panic disorder, social phobia, simple phobia, and obsessive-compulsive disorder. Individuals who met criteria for schizophrenia, major depression, or organic brain disorder were excluded from the sample. The sample included 2471 individuals described for diagnostic group, gender, race, and age in Table 1 . The average was 46.2 years, about $60 \%$ were Caucasian, and $70 \%$ were women. There was an overall significant difference in sex ratio between the diagnostic groups, due mainly to the nearly equal distribution of men and women in the social phobic groups as compared to the preponderance of females in the other groups (unweighted $\chi^{2}(6)=39.67, p<.0001$ ). Although not shown in Table 1 , a multiple anxiety diagnoses group $(n=577)$ included those individuals who

TABLE 1

DEMOGRAPHIC CHARACTERISTICS OF SUBJECTS WITH ANXIETY DISORDERS

\begin{tabular}{lcccccc}
\hline & $\begin{array}{c}\text { Agoraphobia } \\
\text { With Panic } \\
(n=29)\end{array}$ & $\begin{array}{c}\text { Panic } \\
\text { Disorder } \\
(n=51)\end{array}$ & $\begin{array}{c}\text { Agora- } \\
\text { phobia } \\
(n=167)\end{array}$ & $\begin{array}{c}\text { Simple } \\
\text { Phobia } \\
(n=1040)\end{array}$ & $\begin{array}{c}\text { Social } \\
\text { Phobia } \\
(n=61)\end{array}$ & $\begin{array}{c}\text { Obsessive } \\
\text { Compulsive } \\
(n=222)\end{array}$ \\
\hline $\begin{array}{l}\text { Male } \\
N(\%)\end{array}$ & $8(22.2)$ & $17(29.8)$ & $51(25.5)$ & $361(30.7)$ & $37(30.7)$ & $92(35.3)$ \\
$\begin{array}{l}\text { White } \\
N(\%)\end{array}$ & $27(74.0)$ & $45(79.5)$ & $124(63.6)$ & $677(60.6)$ & $49(68.8)$ & $169(71.7)$ \\
Age & 40.2 & 43.2 & 50.5 & 48.2 & 39.3 & 44.4 \\
\hline
\end{tabular}


met criteria for two or three different anxiety disorders (no individuals met criteria for more than three disorders). The most common multiple diagnoses were agoraphobia without panic attacks combined with a simple phobia $(n=438)$ and simple phobia coupled with social phobia $(n=154)$. This mixed group was $21.5 \%$ male, $51.1 \%$ white, and had an average age of 46.8 years.

\section{Procedure}

The prevalence of DSM-III diagnoses of alcohol abuse and/or dependence was estimated within each anxiety disorders group. Weighted least-squares estimates were generated. The weighting variable used was SW3, which weights all sites similarly to account for oversampling of age and certain racial groups at various sites (Eaton \& Kessler, 1985). Dichotomous variables were used for the presence/absence of each anxiety disorder type. The variable utilized to obtain alcohol diagnosis was DSMALC1, which "gives the greatest uniformity across sites, based on equal skip-out patterns and equal treatment of data" (National Institute of Mental Health, 1988, pp. 13-14). This variable identifies respondents who met DSM-III criteria for alcohol abuse and/or dependence. The prevalence of alcohol abuse and/or dependence was calculated as the weighted percent of those meeting criteria for an anxiety disorder who also qualify for alcohol abuse and or dependence.

Logistic regression was used to model presence of alcohol use disorder given the existence of one anxiety disorder, compared to a specific other anxiety disorder. Sex, race (White, Black, other), and age (categorized as 18-24, $25-34,35-44,45-64,65$ or over) were controlled for in these regressions. For these regressions, the criterion variables were dichotomous. For each comparison, subjects with one disorder were assigned a zero, while those with the alternate diagnosis were given a value of one. In the analyses that included subjects with multiple phobias, the comparisons were between, for example, those with a simple phobia and not social phobia versus those with social phobia but not a simple phobia. Anxiety disorders other than the two being contrasted were ignored.

We computed measures of relative risk for an alcohol diagnosis, comparing one anxiety diagnosis to a different anxiety diagnosis. Odds ratios were used to express relative risk. Following Mantel and Haenszel (1959), adjusted odds ratios were calculated using coefficients derived from the logistic regressions. Confidence intervals (95\%) were calculated for these odds ratios; if the confidence interval includes 1.0 , the odds ratio is considered insignificant. This procedure was performed initially with those meeting criteria for one diagnosis only, then repeated including individuals with multiple anxiety diagnoses. A significant odds ratio suggests that the anxiety disorder increases risk for alcoholism relative to the comparison anxiety disorder.

\section{RESULTS}

A total of 296 people in this anxiety sample also had a lifetime history of an alcohol abuse and/or dependence disorder (Table 2a). Although not shown in 
Table $2,17.1 \%(82 / 577)$ of people with more than one anxiety disorder met criteria for alcohol abuse or dependence. The prevalence rate of alcohol disorder ranged from $13.05 \%$ among those with a single diagnosis of simple phobia to $27.68 \%$ among those with a single diagnosis of social phobia. Prevalence of substance abuse disorder was significantly different among the groups (unweighted $\chi^{2}(5)=28.3, p<.0001$ ). When rates in diagnostic groups were compared with each other, a single odds ratio was significant after correcting for multiple comparisons. Individuals with obsessive compulsive disorder were 1.48 times more likely to have a comorbid alcohol diagnosis than simple phobics (Table 3 ). Odds ratios were also calculated without correcting for multiple comparisons, which gave suggestive evidence that agoraphobia with panic attacks increased the odds of an alcohol diagnosis by 2.03 over agoraphobia without panic and 1.93 over simple phobia (Table 3 ).

Using all individuals with either single or multiple anxiety disorders (Table $2 b$ ), the prevalence rate of alcohol use disorders ranged from $12.29 \%$ among those with a diagnosis of agoraphobia without panic to $31.45 \%$ among those suffering from agoraphobia with panic. The chances of qualifying for a concurrent alcohol diagnosis among the simple phobia group and the agoraphobia without panic group did not change in any meaningful way as a result of adding those with multiple diagnoses (although the order of prevalence did change). The agoraphobia with panic group substantially increased the prevalence of alcohol diagnosis to $35.45 \%$ upon adding the multiply diagnosed subjects. This estimate is likely to be a better one because the number of individu-

TABLE 2

Frequency of Alcohol abuse or Dependence Among Persons With Various ANXIETY DISORDERS

a. Mutually-exclusive groups.

\begin{tabular}{lcccccc} 
& $\begin{array}{c}\text { Agoraphobia } \\
\text { With Panic } \\
(n=29)\end{array}$ & $\begin{array}{c}\text { Panic } \\
\text { Disorder } \\
(n=51)\end{array}$ & $\begin{array}{c}\text { Agora- } \\
\text { phobia } \\
(n=167)\end{array}$ & $\begin{array}{c}\text { Simple } \\
\text { Phobia } \\
(n=1040)\end{array}$ & $\begin{array}{c}\text { Social } \\
\text { Phobia } \\
(n=61)\end{array}$ & $\begin{array}{c}\text { Obsessive } \\
\text { Compulsive } \\
(n=222)\end{array}$ \\
\hline Frequency & 8 & 10 & 19 & 116 & 12 & 49 \\
$\begin{array}{l}\text { Percent } \\
\text { (weighted) }\end{array}$ & 23.6 & 17.1 & 13.1 & 13.7 & 27.7 & 24.3 \\
\hline
\end{tabular}

b. Groups with one or more diagnoses.

\begin{tabular}{cccccc}
$\begin{array}{c}\text { Agoraphobia } \\
\text { With Panic } \\
(n=70)\end{array}$ & $\begin{array}{c}\text { Panic } \\
\text { Disorder } \\
(n=70)\end{array}$ & $\begin{array}{c}\text { Agora- } \\
\text { phobia } \\
(n=576)\end{array}$ & $\begin{array}{c}\text { Simple } \\
\text { Phobia } \\
(n=1560)\end{array}$ & $\begin{array}{c}\text { Social } \\
\text { Phobia } \\
(n=238)\end{array}$ & $\begin{array}{c}\text { Obsessive } \\
\text { Compulsive } \\
(n=249)\end{array}$ \\
\hline 20 & 15 & 64 & 185 & 38 & 55 \\
31.5 & 20.4 & 12.3 & 14.4 & 21.9 & 24.6
\end{tabular}


TABLE 3

Adjusted Odds Ratios Using Sample of People Wrth OnLy ONe ANXIETY DISORDER

\begin{tabular}{ll}
\hline Comparison & $\begin{array}{c}\text { Adjusted Odds Ratio } \\
(95 \% \text { C.I) }\end{array}$ \\
\hline Simple phobia vs agoraphobia with panic & $1.93(1.21-3.08)^{*}$ \\
Simple phobia vs panic & $1.32(.88-1.97)$ \\
Simple phobia vs agoraphobia & $1.10(.83-1.46)$ \\
Simple phobia vs social phobia & $1.13(.78-1.64)$ \\
Simple phobia vs OCD & $1.48(1.20-1.81)^{* *}$ \\
Social phobia vs agoraphobia with panic & $0.55(.28-1.08)$ \\
Social phobia vs panic disorder & $0.83(.46-1.51)$ \\
Social phobia vs agoraphobia & $0.93(.57-1.51)$ \\
Social phobia vs OCD 2 & $0.80(.53-1.2)$ \\
Agoraphobia with panic vs panic disorder & $2.11(.89-4.94)$ \\
Agoraphobia with panic vs agoraphobia & $2.30(1.10-3.76)^{*}$ \\
Agoraphobia with panic vs OCD 2 & $1.52(.9-2.55)$ \\
\hline
\end{tabular}

1 Odds ratios are adjusted for age, sex, and race

2 Obsessive compulsive disorder

nominal $p<.05$

** $p<.05$ after adjusting for 12 simultaneous comparisons

als in the agoraphobia and panic group increased from 29 to 70 subjects. Social phobics, when we allowed for multiple diagnoses, no longer were found to be the most likely of the anxiety disordered to report a concurrent alcohol diagnosis. This change in prevalence appears to be in part because of the addition of 177 people to the social phobic group, increasing the sample size to 238 subjects. These additional subjects likely result in a more representative sample of social phobics. The prevalence of concurrent alcohol diagnosis among obsessive compulsive individuals was virtually unchanged after adding the few multiply diagnosed individuals with OCD.

Table 4 shows the odds ratios when individuals with multiple anxiety diagnoses were included with the subjects with a single diagnosis. Suggestive evidence was found for agoraphobia with panic attacks to increase the odds of an alcohol diagnosis by 1.9 over simple phobia and 1.5 over obsessive compulsive disorder. Again, alcohol use disorders were significantly more prevalent in the agoraphobia with panic group than in the agoraphobia without panic, social phobia, simple phobia, and obsessive compulsive disorder groups.

\section{DISCUSSION}

Alcohol abuse and/or dependence was least likely to be present among the agoraphobia without panic and the simple phobia groups, regardless of whether single or multiple diagnoses were utilized. The highest prevalence rates of alcohol diagnoses were found among agoraphobics with panic attacks. When every individual with an anxiety disorder was included, agoraphobics with panic attacks were significantly at higher risk (about 1.5 times higher) 
TABLE 4

adjusted Odds Ratios Using Sample of People With ONE OR More ANXIETY DISORDERS

\begin{tabular}{ll}
\hline Comparison & $\begin{array}{c}\text { Adjusted Odds Ratio } \\
(95 \% \text { C.I) }\end{array}$ \\
\hline Simple phobia vs agoraphobia with panic & $1.95(.97-3.91)^{*}$ \\
Simple phobia vs panic & $1.12(.65-1.91)$ \\
Simple phobia vs agoraphobia & $1.03(.70-1.50)$ \\
Simple phobia vs social phobia & $1.19 .(.80-1.78)$ \\
Simple phobia vs OCD & $1.33(1.02-1.75)^{* *}$ \\
Social phobia vs agoraphobia with panic & $0.52(.28-.95)^{* *}$ \\
Social phobia vs panic disorder & $0.81(.45-1.45)$ \\
Social phobia vs agoraphobia & $0.96(.64-1.45)$ \\
Social phobia vs OCD 2 & $0.82(.55-1.21)$ \\
Agoraphobia with panic vs panic disorder & $1.47(.75-2.87)$ \\
Agoraphobia with panic vs agoraphobia & $1.87(1.13-3.07)^{* *}$ \\
Agoraphobia with panic vs OCD & $1.51(.89-2.56)^{*}$ \\
\hline
\end{tabular}

lodds ratios are adjustod for age, sex, and rece

2 Obsessive compulsive disorder

*nominal $p<.05$

${ }^{*} p<.05$ after adjusting for 12 simultancous comparisons

than all other groups. One interesting question from these data is why does the agoraphobia without panic attack group contain fewer alcoholics than the agoraphobia with panic group? This result is likely due to an oddity in the DIS interview that can result in an individual with a single fear of tunnels or bridges, crowds, driving, and/or riding in other forms of transportation receiving a diagnosis of agoraphobia without panic attacks. Many of these individuals with a single phobia would be more appropriately diagnosed as suffering from simple phobia rather than agoraphobia without panic. Given this fact, one would expect the prevalence of alcoholism within the agoraphobia without panic group to closely resemble the prevalence within simple phobia group, which was indeed found in this study.

The results of the present study are in agreement with Thyer et al. (1986), in that the agoraphobia with panic group contained many individuals with alcohol problems. Both studies found prevalence rates of nearly $30 \%$ for concurrent alcohol problems. Reich and Chaudry also found prevalence rates of nearly $30 \%$ in a mixed group of panic disorder and agoraphobia with panic disorder patients. In addition, Bibb and Chambless (1986) also found high MAST scores among agoraphobics with panic attacks (21\%). Simple phobics were found to be low in concurrent alcohol problems in both studies. As for those with a single diagnosis of social phobia, the results of both Thyer et al. (1986) and the present study are inconclusive. Numerically, the social phobia group contained a large percentage of alcoholics, but in neither study was this significantly higher than other groups. The present study found a greater percentage of comorbid social phobia and alcoholism than did Schneier et al. (1989). 
There is reason to view these results with some caution given the following limitations of the Epidemiologic Catchment Area Study. The use of nonclinician interviewers is a common pitfall of epidemiologic research. However, the Diagnostic Interview Schedule has been found to have high test-retest agrcement between trained interviewers and clinicians using other assessment methods (Burke, 1986), especially among the substance abuse disorders. Testretest results for anxiety disorders have been less consistent (Burke, 1986).

These results offer some guidelines that may have an effect on clinical treatment of anxiety disorders. Clinicians apparently need to be especially careful in ruling out comorbid alcohol abuse and/or dependence among agoraphobics with panic attacks. Nearly $30 \%$ of agoraphobia with panic patients in this study qualified for a comorbid alcohol diagnosis. The reasons for this difference could lie in the polyphobic nature of agoraphobia with panic as described by Thyer et al. (1986). In fact, the similarity of symptoms of alcohol withdrawal and panic disorder can make comorbid diagnosis of alcoholism and panic disorder (with or without agoraphobia) difficult (Weissman, 1988a). Family studies of agoraphobics also have found a larger than expected number of relatives with alcohol difficulties. This finding suggests either a history of self-medication or an underlying shared biological deficit (Crowe et al. 1983; Munjack \& Moss, 1981). Clinicians also need to be attuned to the possibility of comorbid alcoholism among social phobics and obsessive-compulsives given their prevalence rates of over $20 \%$. Simple phobics do not seem to differ from the general population with respect to concurrent alcohol abuse/dependence (Weissman, 1988b), which may be because they do not gain relief from phobic anxiety by using alcohol upon exposure to phobic stimuli (Thyer \& Curtis, 1984).

\section{REFERENCES}

Bibb, J. L., \& Chambless, D. L. (1985). Alcohol usc and abuse among diagnosed agoraphobics. Behaviour Research and Therapy, 23, 49-58.

Boyd, J. H., Burke, J. D., Gruenberg, E., Holzer, C. E., Rae, D. S., George, L. K., Karno, M., Soltzman, R., McEvoy, L., Nestadt, G. (1984). Exclusion criteria of DSM-III. Archives of General Psychiatry, 41, 983-989.

Burke, J. D. (1986). Diagnostic categorisation by the DIS: Comparison with other methods of assessment. New York: Guilford Press.

Christie, K. A., Burke, J. D., Regier, D. A., Rae, D. S., Boyd, J. H., \& Loke, B. Z. (1988). Epidemiologic evidence for early onset of mental disorders and higher risk of drug abuse in young adults. American Journal of Psychiatry, 145, 971-975.

Crowe, R. R., Noyes, R., Pauls, D. L., \& Slymen, D. (1983). A family study of panic disorder. Archives of General Psychiatry, 40, 1065-1069.

Eaton, W. W., \& Kessler, L. G. (1985). Epidemiologic field methods in psychiatry: The NIMH Epidemiologic Catchment Area Program. Orlando, Florida: Academic Press.

George, D. T., Zerby, A., Noble, S., \& Nut, D. T. (1988). Panic attacks and alcohol withdrawal: Can subjects differentiate the symptoms? Biological Psychiatry, 24, 240-243.

Helzer, J. H., \& Pryzbeck, T. R. (1988). The co-occurence of alcoholism with other psychiatric disorders in the general population and its impact on treatment. Journal of Studies on Alcohol, 49, 219-224.

Hesselbrock, A. N., Meyer, R. E., \& Keener, S. J. (1985). Psychopathology in hospitalized alcoholics. Archives of General Psychiatry, 42, 1050-1055. 
Hodgson, R., Stockwell, T., \& Rankin, H. (1979). Can alcohol reduce tension? Behaviour Research and Therapy, 17, 459-466.

Mullaney, J. A., \& Trippett, C. J. (1979). Alcohol dependence and phobias: Clinical description and relevance. British Journal of Psychiatry, 135, 565-573.

Munjack, D. J., Moss, H. B. (1981). Affective disorder and alcoholism in families of agoraphobics. Archives of General Psychiatry, 38, 869-871.

Myers, J. K., Weissman, M. M., Tischler, G. L., Holzer, C. E., Leaf, P. J., Orvasche., H., Anthony, H., Boyd, J. H., Burke, J. D., Kramer, M. \& Soltzman, R. (1984). Six-month prevalence of psychiatric disorders in three communities: 1980-1982. Archives of General Psychiatry, 41, 959-967.

National Institute of Mental Health (1988). NIMH Epidemiological Catchment Area Survey: Wave I Household Sample. (DHHS Publication No. PB88-189014). Washington, DC: Govemment Printing Office.

Nunes, E., Quitkin, F., \& Berman, C. (1988). Panic disorder and depression in female alcoholics. Journal of Clinical Psychiatry, 49, 441-443.

Reich, J., \& Chaudry, D. (1987). Personality of panic disorder alcohol abusers. Journal of Nervous and Mental Disease, 175, 224-228.

Ross, H. E., Glaser, F. B., \& Germanson, T. (1988). The prevalence of psychiatric disorders in patients with alcohol and other drug problems. Archives of General Psychiatry, 45, 1023-1031.

Schneier, F. R., Martin, L. Y., Leibowitz, M. R., Gorman, J. M., \& Fyer, A. J. (1989). Alcohol abuse in social phobia. Journal of Anxiety Disorders, 3, 15-23.

Selzer, M. L. (1971). The Michigan alcoholism screening test; The quest for a new diagnostic instrument. American Journal of Psychiatry, 127, 1653-1658.

Smail, P., Stockwell, T., Canter, S., \& Hodgson, R. (1984). Alcohol dependence and phobic anxiety states. British Journal of Addiction, 82, 971-979.

Stockwell, T., Hodgson, R., \& Rankin, H. (1982). Tension reduction and effects of prolonged alcohol consumption. British Journal of Addiction, 77, 65-73.

Thyer, B. A., \& Curtis, G. C. (1984). The effects of ethanol intoxication on phobic anxiety. Behaviour Research and Therapy, 22, 599-610.

Thyer, B. A., Parrish, R. T., Himle, J., Cameron, O. G., Curtis, G. C., \& Nesse, R. A. (1986). Alcohol abuse among clinically anxious patients. Behaviour Research and Therapy, 24, 357-359.

Weiss, K. J., \& Rosenberg, D. J. (1985). Prevalence of anxiety disorder among alcoholics. Journal of Clinical Psychiatry, 46, 3-5.

Wcissman, M. (1988a). Anxicty and alcoholism. Journal of Clinical Psychiatry, 49, 17-19.

Weissman, M. (1988b). The epidemiology of anxiety disorders: Rates, risks and familial patterns. Journal of Psychiatric Research, 22, 99-114. 